Original Research Article

\title{
Comparative study of topical application of nanosilver and human placental extract on wound healing in rabbits
}

\author{
Umamaheshwara Raju S. $^{1}$, T. S. Usha Sree ${ }^{1}$, Karuna Sree Podila ${ }^{2 *}$, Vijay Krishna ${ }^{1}$
}

${ }^{1}$ Department of Pharmacology, Gandhi Medical College, Secunderabad, Telangana, India ${ }^{2}$ Department of Pharmacology, ESIC Medical College, Sanathnagar, Hyderabad, Telangana, India

Received: 14 July 2017

Accepted: 19 July 2017

*Correspondence to:

Dr. Karuna Sree P.,

Email: drpkarunasri@gmail.com

Copyright: () the author(s), publisher and licensee Medip Academy. This is an openaccess article distributed under the terms of the Creative Commons Attribution NonCommercial License, which permits unrestricted noncommercial use, distribution, and reproduction in any medium, provided the original work is properly cited.

\begin{abstract}
Background: The objective of the study was to study the comparative effect of topical application of nanosilver and human placental extract on wound healing in rabbits.

Methods: 12 rabbits were randomly divided into two groups $(n=6)$ and wound healing effect was observed in Excision model. Standard group was treated with topical human placental extract gel and test group was treated with topical Nanosilver cream. The mean percentage of the wound healed 'within' the group and 'in between' the groups were observed on day 3, 6, 9, 12, 15, 18, 21 and biopsy was done on day 21 for histopathological examination.

Results: The mean percentage of wound contracted with Human placental extract vs nanosilver was 29.5 vs 35.7 on day3, 46.2 vs 53.5 on day $6,61.5$ vs 70.2 on day9, 74.2 vs 88.0 on day12, 89.5 vs 97.0 on day $15,96.7$ vs 99.9 on day 18 and 99.9 vs 100 day 21 respectively. The mean percentage of the wound contracted when day1 compared to day21 was statistically significant ( $\mathrm{P}$ value 0.0001$)$ within the groups but in between the groups it was statistically non significant ( $\mathrm{P}$ $>0.05$ ). There was an increase in collagen content and granulation tissue in the histopathological examination in both the groups on day 21 .

Conclusions: Wound healing effect of the Nanosilver was comparable to that of Human placental extract in excision wound model of rabbit.
\end{abstract}

Keywords: Human placental extract, Nanosilver, Wound healing

\section{INTRODUCTION}

Wound is defined as the disruption of cellular and anatomical continuity of tissue integrity and sometimes associated with loss of function. Wounds are due to surgical, physical, chemical and microbial injuries. Wounds are the main cause of physical disabilities. Though the wounds commonly involve the skin, they are highly diverse in their aetiology. Restoration of damaged tissue plays a vital role in survival of life and it is imminent for basis of all surgical manipulations. Healing occurs after practically any insult that causes tissue destruction and is essential for survival of the organism. ${ }^{1}$
Healing is the body response to injury in an attempt to restore normal structure and function. Healing of wounds is an important biological process with well organized biochemical and cellular events leading to tissue repairs and regeneration in a special manner. Wound is regarded as healed when there is restoration of the wounded tissue to the normal condition.

The aim of wound care is to promote wound healing in the shortest time possible, with minimal pain, discomfort, and scarring to the patient and must occur in a physiologic environment conducive to tissue repair and regeneration. ${ }^{2}$ 
Extrinsic factors affecting wound healing include: Mechanical stress, Debris, Temperature, Desiccation and maceration, Infection, Chemical stress, Medications, Alcohol abuse, Smoking, and Radiation therapy. Intrinsic factors that directly affect the performance of healing are: Health status, Age factors, Body built and Nutritional status.

Current estimates indicate that nearly 6 million people suffer from chronic wounds worldwide. There are very few Indian studies on the epidemiology of chronic wounds. The prevalence of the chronic wounds in the community was reported as 4.5 per 1000 population, where as that of acute wounds was nearly double, at 10.5 per 1000 population. ${ }^{3}$ In the course of lifetime $10 \%$ of population will develop a chronic wound, with a related morbidity and mortality rate of $2.5 \%$. Every 30 seconds a lower limb is lost somewhere in the world as a consequence of Diabetes mellitus. ${ }^{4}$

Many new approaches like gene therapy, tissue engineered skin have met with limited success. Therefore, there is an increasing interest to develop novel agents that promote wound healing.

The use of natural products has been one of the successful strategies for discovery of new drugs. Some of these have been screened scientifically for their wound healing activity in different pharmacological models and patients, but the potential of most remains unexplored. ${ }^{5}$ In the present study the evaluation of wound healing property of nanosilver was compared with $10 \%$ aqueous Human placental extract (HPE) in rabbits by excision models, as topical application once daily.

\section{METHODS}

The study was undertaken to evaluate "The wound healing effect of Human placental extract in comparison with Nanosilver in Rabbits", in the Department of Pharmacology, Gandhi Medical College, Secunderabad, after obtaining prior approval from Institutional Animal Ethics Committee, GMC on 17-06-2016. Experimental work and formulations were carried out under sterile conditions.

\section{Animals}

Procured from Central animal house (reg.no.428/01C/CPCSEA), Department of Pharmacology, GMC Secunderabad. Healthy rabbits of both sexes of weighing $1.5-2.5 \mathrm{kgs}$ were used in the present study.

The Rabbits were randomly selected for both the groups after 7 days of acclimatization period. They were housed in appropriately labelled steel cages according to groups in a room maintained at $12 \mathrm{hr}$ light-dark cycles and at a constant temperature of $24 \pm 2{ }^{\circ} \mathrm{C}$. The rabbits were provided with food consisting of Lucin grass, chana and water ad libitum.

The excision wound model was chosen to study, as the healing process is by secondary intention. ${ }^{6}$ If tissue injury is severe or chronic, and results in damage of both parenchymal and stromal frame work of the tissue, healing cannot be accomplished by regeneration. Repair by deposition of collagen and other extra cellular matrix (ECM) components, causing the formation of a scar is inevitable. Hence the excision biopsy was taken to confirm the increase in collagen content. The present study was based on the wound healing efficacy of the nanosilver in comparison with the standard drug HPE, evaluated in excision wound model. Number of animals in each group was 6 Rabbits (Table 1). Purified HPE is available as a gel preparation for external application on wound and Nano silver is available as ointment for topical application was used in the experiment.

Table 1: Grouping of animals.

\begin{tabular}{|lll|}
\hline Excision model & Drug & No of rabbits \\
\hline Group A & Nanosilver & 06 \\
\hline Group B & $\begin{array}{l}\text { Human placental } \\
\text { extract }\end{array}$ & 06 \\
\hline
\end{tabular}

\section{Excision wound model}

The Rabbits were anaesthetized by intramuscular injection of ketamine $2.5 \mathrm{mg} / \mathrm{kg}$. Under local infiltration of $2 \%$ xylocaine, the animals were shaved on the back and the skin was disinfected using spirit cotton. The anticipated area of the wound to be created was outlined on the back of the animals with methylene blue. A square shaped full thickness excision wound $400 \mathrm{~mm}^{2}$ of $2 \mathrm{~mm}$ depth was created along the markings, using sterile toothed forceps, scalpel and pointed scissors, in the para vertebral area, $2 \mathrm{~cm}$ from midline, over the back (Figure 1).

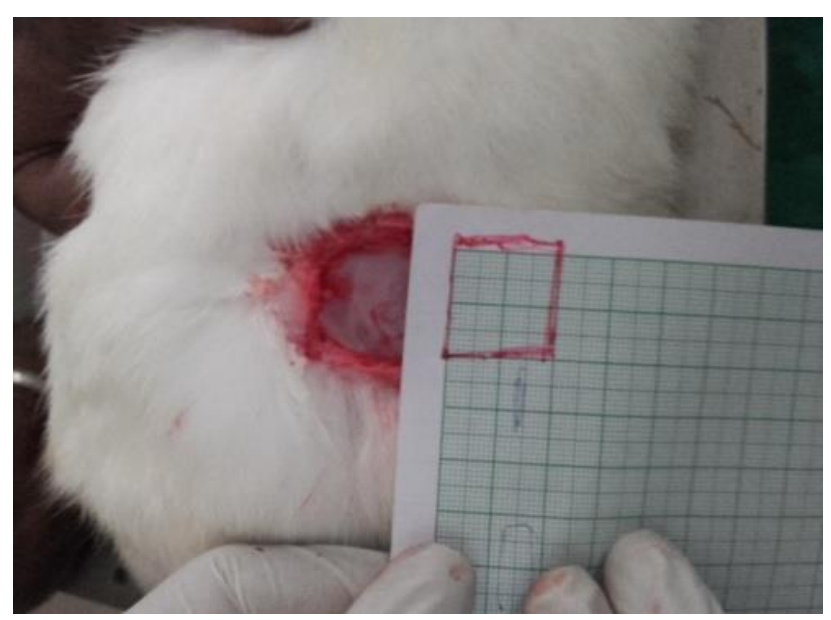

Figure 1: Excision wound (400Sqmm) on Rabbit.

The same procedure was performed for all the Rabbits. The Nanosilver ointment to test group, Human placental 
extract gel to standard group were applied topically, once daily till the complete epithelialisation, starting from the day of operation, the day one (Figure 2). The parameters studied were wound closure and epithelialisation time.

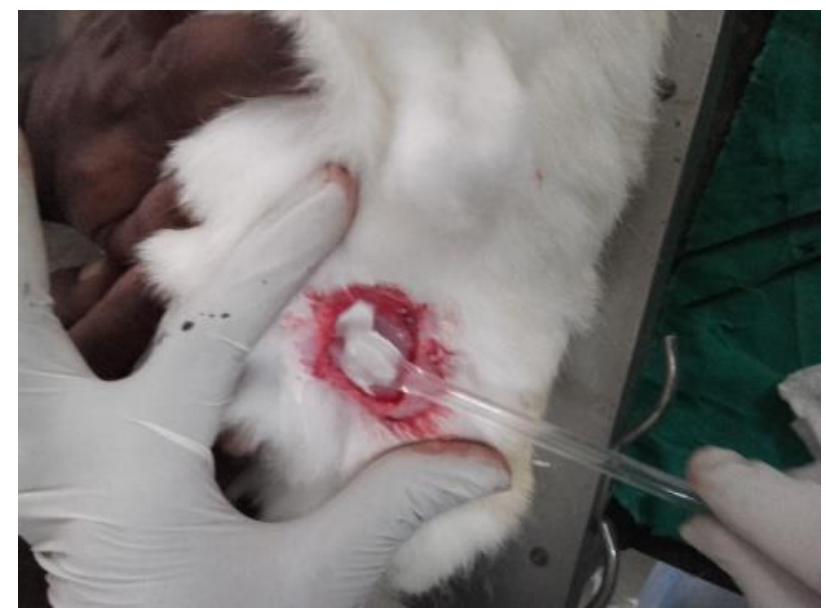

Figure 2: Topical application of ointment.

To measure the contracture of the wounds, a transparent plastic paper was placed on the location of the wound and its shape was drawn on the same paper with a marker. These wound tracings were retraced on a millimeter scale graph paper to determine the wound area, expressed as in $\mathrm{mm}^{2}$. The wounds were measured in the same position, at regular intervals. The wounds were traced on graph paper on day $3,6,9,12,15,18$ and 21 of the experiment.

The total number of days required for complete epithelialisation of the wound was noted in each rabbit, in both the groups. The number of days required for falling of the scar without any residual raw wound, was the period of epithelialisation, around $16-20$ days. On $21^{\text {st }}$ day the excision biopsy was taken, including the adjacent normal skin and sent for Histopathological Examination, to confirm the increase in collagen tissue and granulation tissue.

\section{RESULTS}

The present study was based on the wound healing efficacy of Nanosilver in comparison with the standard drug HPE by excision wound model in rabbit. Excision model was selected to study wound healing by secondary intention. A square shaped full thickness excision wound of $400 \mathrm{~mm}^{2}$ with $2 \mathrm{~mm}$ depth was created. The wound area contracted and percentage of wound healed measured on day $3,6,9$, $12,15,18$ and 21.

Contracture of the wounds was measured using a transparent plastic paper placed on the wound and its shape was drawn on the same paper with a marker. These wound tracings were retraced on a millimeter scale graph paper to determine the wound area, expressed as in $\mathrm{mm}^{2}$. The wounds were measured in the same position, at regular intervals, on day $3,6,9,12,15,18$ and 21 of the study (Figure 3 and Figure 4).

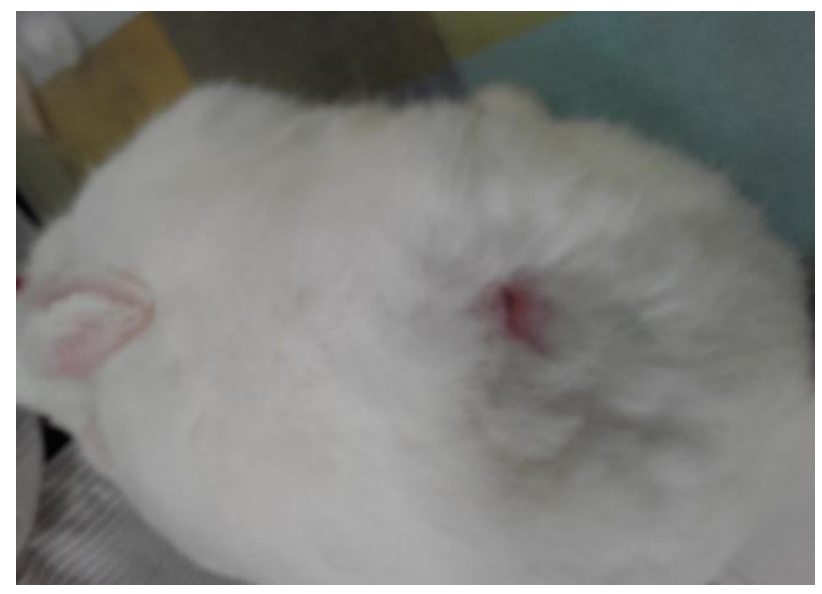

Figure 3: Wound healing effect of Nanosilver on day 16 with mean wound area $12 \pm 5.6 \mathrm{Sq} \mathrm{mm}$.

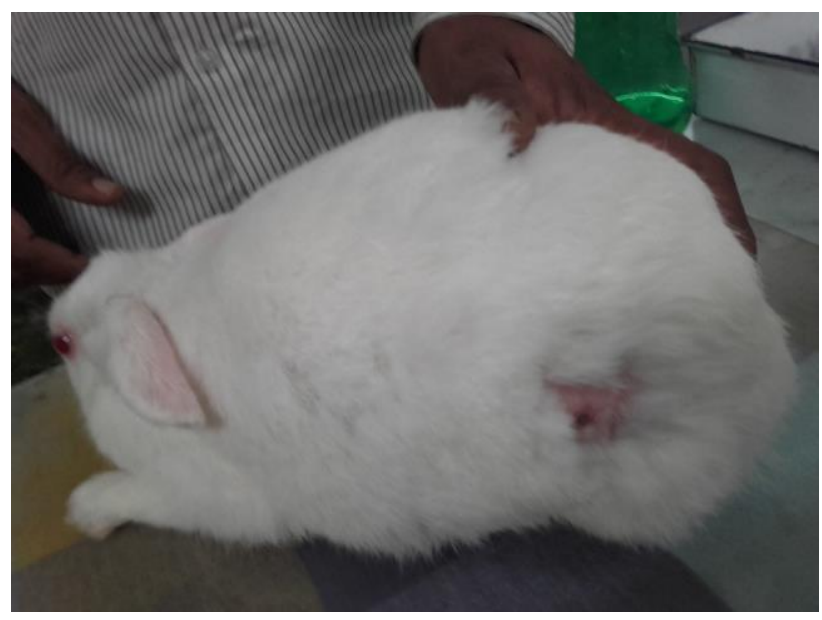

Figure 4: Day 16-wound healing effect of $10 \%$ HPE with man wound area of $42 \pm 12 S q ~ m m$.

The percentage of wound healed was calculated. The period of epithelialisation was calculated as the number of days required for falling of the scab. Healed scar was excised including the adjacent normal skin and sent for HPE on day 21, in both the groups.

The mean percentage of the wound healed calculated on day $3,6,9,12,15,18$ and 21 (Table 2). The mean percentage of the wound contracted on day $3,6,9,12,15$, 18 and 21 with Nanosilver when compared to Human placental extract was given in Table 2. There was no statistically significant difference $(\mathrm{P}$ value $>0.05)$ in the mean percentage of wound contracted in between the two groups when compared on days 3, 6, 9, 12, 15, 18 and 21, indicating that wound healing effect of nanosilver was comparable to that of $10 \% \mathrm{HPE}$. When the statistical analysis was done for the mean percentage of wound healed within the groups, when Day1 compared to Day 21, there was a significant difference (P value - 0.0001$)$ with in' the groups. 
Table 2: Mean wound area and mean percentage of wound healed in group $A$ and $B$ on respective days.

\begin{tabular}{|lllll|}
\hline Days & \multicolumn{2}{l}{$\begin{array}{l}\text { Mean wound area } \\
\left(\mathbf{m m}^{\mathbf{2}}\right)\end{array}$} & $\begin{array}{l}\text { Mean percentage of } \\
\text { wound healed (\%) }\end{array}$ \\
\hline & Group A & Group B & Group A & Group B \\
\hline Day1 & $400 \pm 37$ & $400 \pm 23$ & 0 & 0 \\
\hline Day3 & $257 \pm 28$ & $282 \pm 29$ & 35.7 & 29.5 \\
\hline Day6 & $186 \pm 33$ & $215 \pm 18$ & 53.5 & 46.2 \\
\hline Day9 & $119 \pm 17$ & $154 \pm 34$ & 70.2 & 61.5 \\
\hline Day12 & $48 \pm 14$ & $103 \pm 25$ & 88.0 & 74.2 \\
\hline Day15 & $12 \pm 5.6$ & $42 \pm 12$ & 97.0 & 89.5 \\
\hline Day18 & $2.0 \pm 0.5$ & $13 \pm 7.1$ & 99.9 & 96.7 \\
\hline Day21 & 0 & $2.0 \pm 1.3$ & 100 & 99.9 \\
\hline P value & 0.65 & & 0.53 & \\
\hline
\end{tabular}

The mean wound size measured in $\mathrm{mm}^{2}$ on day $3,6,9,12$, 15,18 and 21 in both groups (Table 2).

Biopsy on day 21 reflected, increase in collagen content and granulation tissue on histopathological examination in both the groups. (Figure 5, Figure 6, Figure 7 and Figure $8)$.

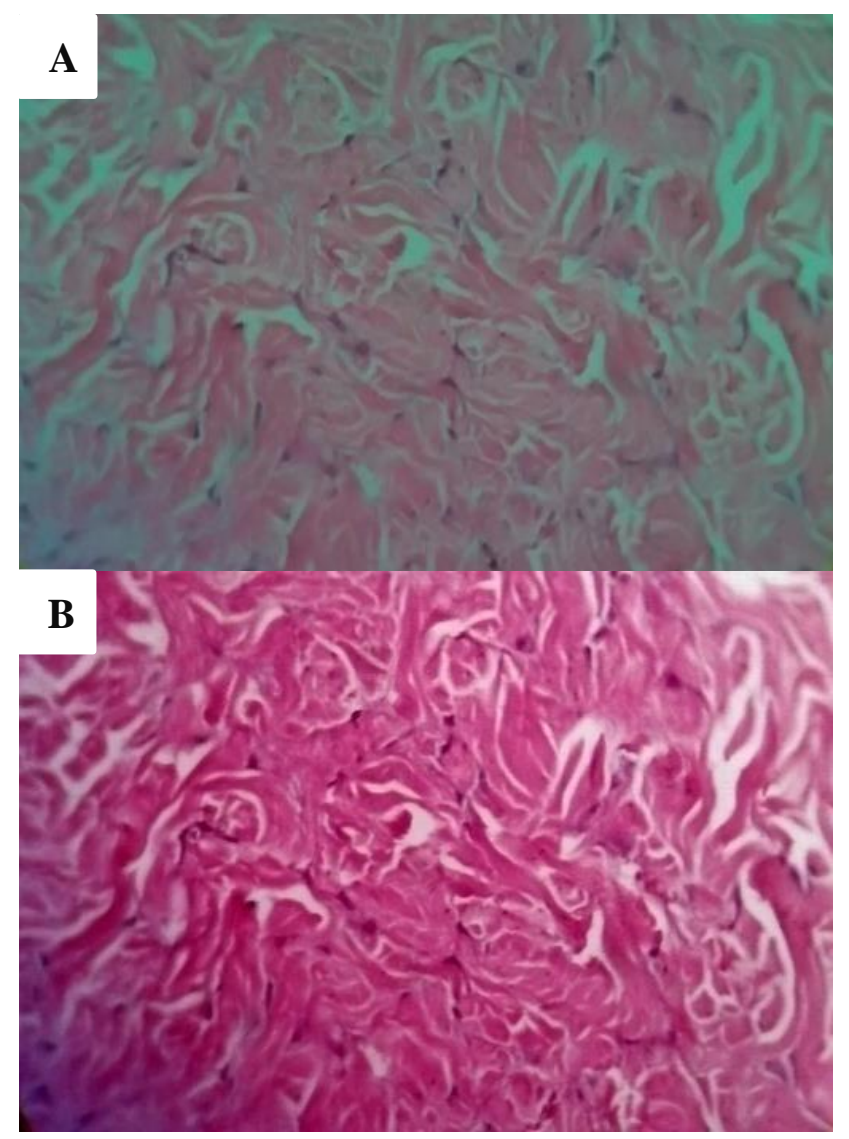

Figure 5 (A and B): Histopathological examination of scar on day 21 in group A (NANOSILVER) showing collagen tissue.
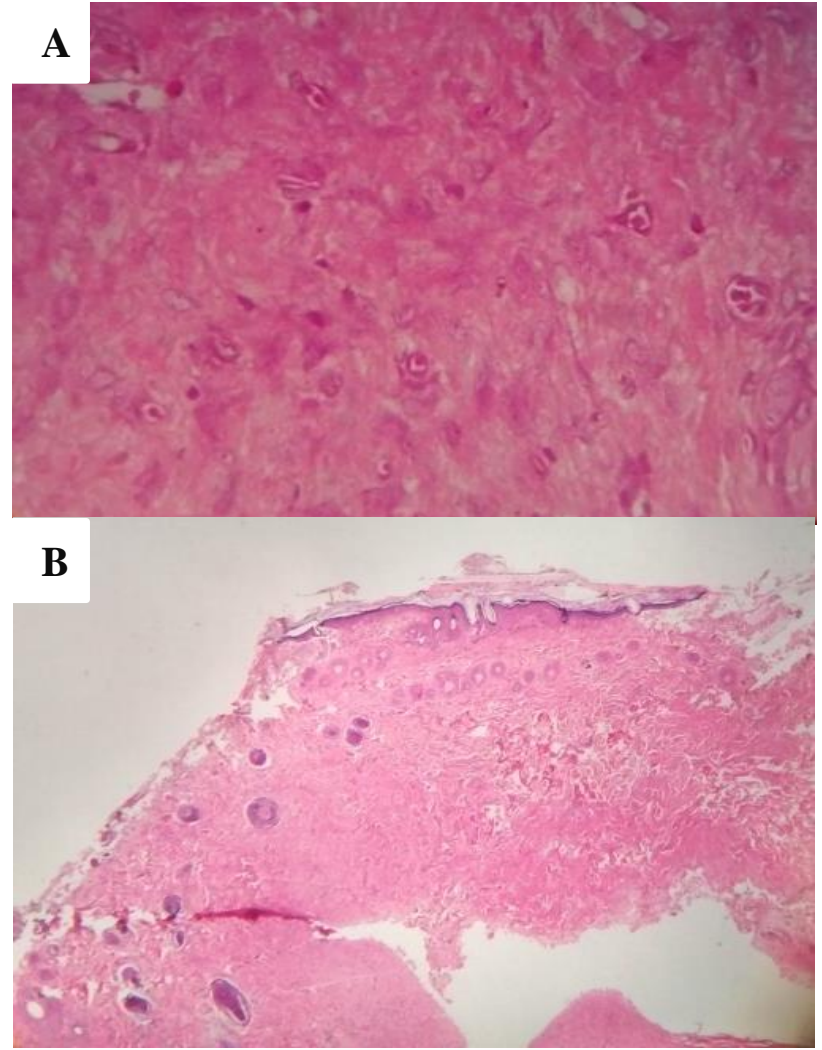

Figure 6 (A and B): Histopathological examination of scar on day 21 in group A (nanosilver) showing granulation tissue.

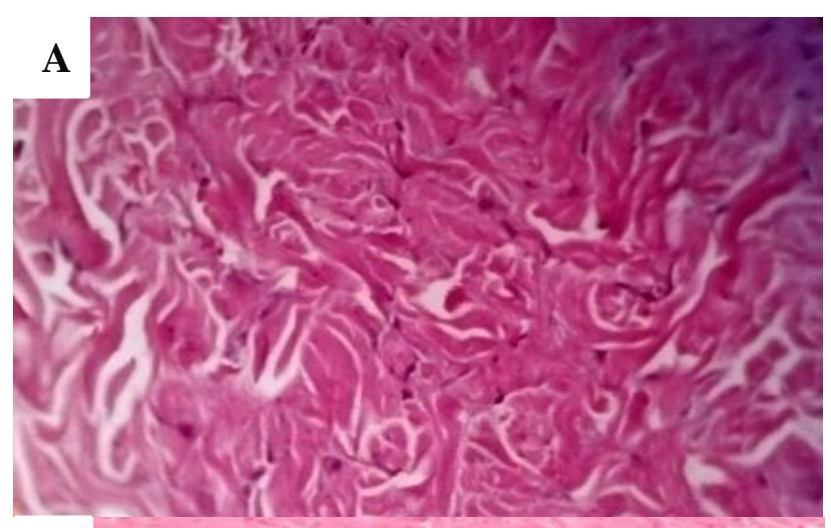

B

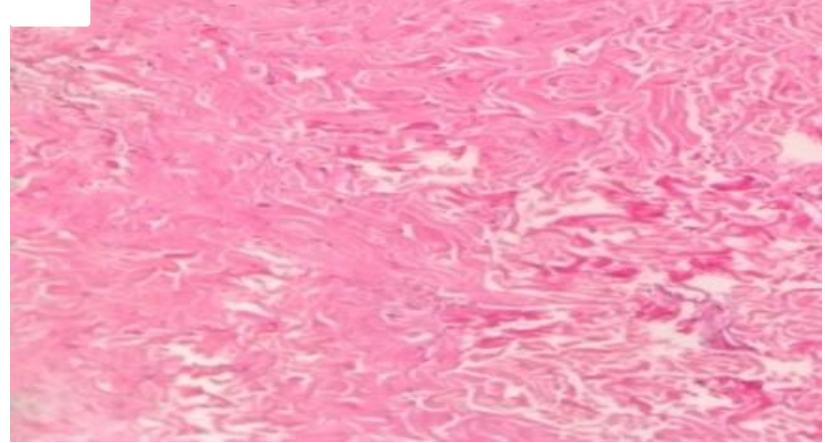

Figure 7 (A and B): Histopathological examination of scar on day 21 in group B (human placental extract) showing collagen tissue. 


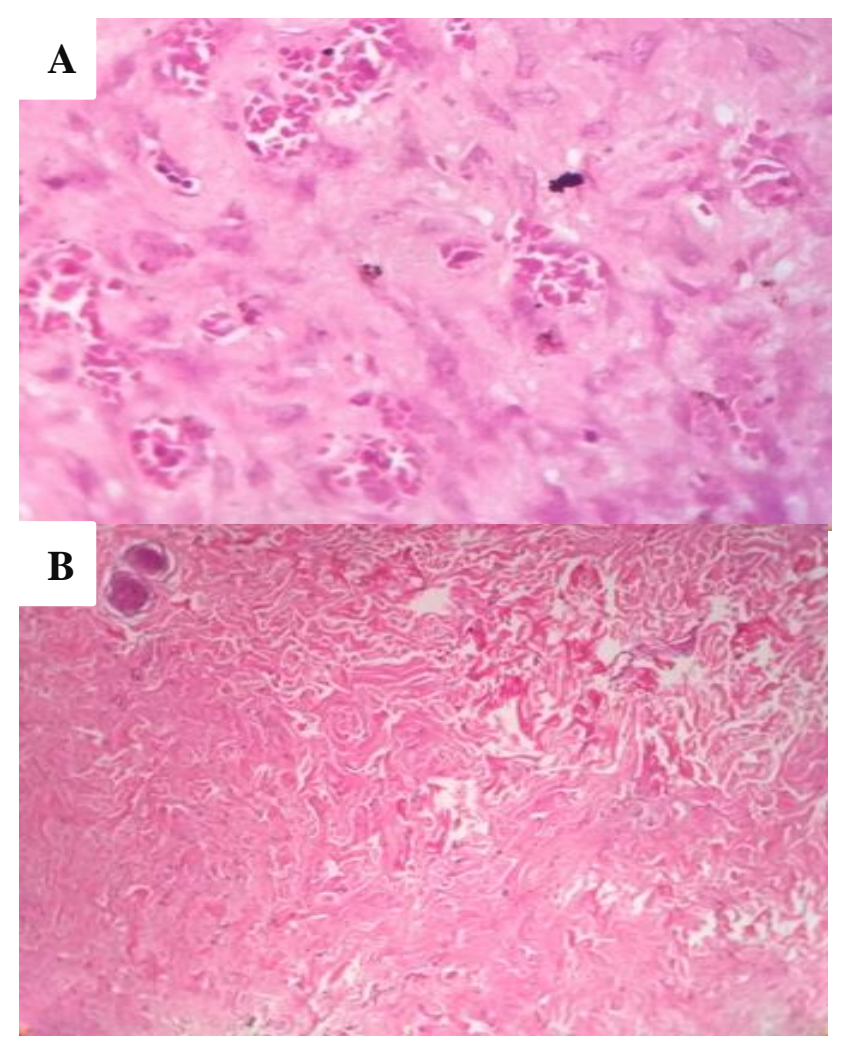

Figure 8 (A and B): Histopathological examination of scar on day 21 in group B (human placental extract) showing granulation tissue.

\section{DISCUSSION}

The present study was based on the wound healing efficacy of Nanosilver in comparison with the standard drug HPE by excision wound model in rabbit. Excision model was selected to study wound healing by secondary intention. The parameters studied were wound closure and epithelialisation time. In this study, we observed that the wound healing effect of nanosilver was comparable to that of 10\% Human Placental Extract (HPE), as there was no statistically significant difference $(\mathrm{P}$ value $>0.05)$ in the mean percentage of the wound contracted between 2 groups; Human placental extract vs. Nanosilver.

On statistical analysis of the study parameters, the mean values of percentage of the wound healed, was significant, $P$ value 0.0001 , 'with in' the groups when Day 1 compared to Day 21. Biopsy on day 21 reflected, increase in collagen content and granulation tissue in the HPE of both the groups.

In the present study, complete epithelialisation was observed after 15 days. Nanosilver on topical application twice daily promoted and potentiated the wound healing as indicated by improved rates of epithelialisation and wound contraction comparable to that of topical Human placental extract, $10 \%$ anionic based applied twice daily. Similar results were observed in the previous studies on wound healing effect of HPE. ${ }^{7}$
Silver compounds have been in use since ancient times. ${ }^{8}$ As Silver nano particles are easy to synthesize by various methods which are simple, safe and economical and in different shapes, sizes and because of negative charge on surface which makes them highly reactive makes the silver nano particles area of interest for researchers to explore. ${ }^{9}$

The probable mechanisms for wound healing activity of nanosilver were as below:

- Broad spectrum antibacterial activity against both gram positive and gram negative bacteria and bacterial resistance is extremely rare, suggesting the presence of multiple bactericidal mechanisms acting in synergy. ${ }^{10,11}$

- As they can be easily incorporated into dressings, with no adverse effects and efficient anti-inflammatory property helps to promote the wound healing by reducing cytokine release, decreasing lymphocyte and mast cell infiltration. ${ }^{12,13}$

The wound healing property of HPE may be attributed to its anti inflammatory and anti aging properties. ${ }^{14}$ It improves the regional blood flow and quickens the tissue regeneration and allows wound healing with minimal scarring. ${ }^{14}$

Hence, in the present study, we observed wound healing effect of nanosilver was comparable to that of $10 \%$ HPE. Limitations of the present study were that there was no standard drug group to compare with treatment groups.

\section{CONCLUSION}

In the present study, the Human placental extract, nanosilver was tested in the excision model for healing in rabbits with 6 Rabbits in each group. It was found that nanosilver has got immense wound healing property comparable to that of HPE.

\section{ACKNOWLEDGEMENTS}

Authors would like to thank teaching and non-teaching staff of Department of Pharmacology, Gandhi Medical College, Secunderabad, for their support in completing this study.

Funding: No funding sources

Conflict of interest: None declared

Ethical approval: The study was approved by the Institutional Animal Ethics Committee, Gandhi Medical College, Secunderabad

\section{REFERENCES}

1. Robbins and Cotran. Tissue Renewal, Regeneration, and Repair; Robbins and Cotran Pathologic Basis of Disease. $8^{\text {th }}$ Edition; Chapter 3; 2011:79-108. 
2. Bowler PG, Duerden BI, Armstrong DG. Wound microbiology and associated approaches to wound management. Clin Microbiol Rev. 2001;(14):244-69.

3. Shukla K, Ansari MA. An Indian community based epidemiological study of wounds. J Wound Care. 2004;(13):323-5.

4. Sasank CS. Venous ulcer of lower limb, where do we stand?. Indian J Plast Surg. 2012;48(2):260-74.

5. Alam G. Wound healing potential of some medicinal plants. Int J Pharm Sci Rev Res. 2011 July-Aug;9(1).

6. Davidson JM. Experimental Animal Wound Models. Wounds; (C) 2001 Health Management Publications, Inc. 2001;13(1):1-6.

7. Chandanwale A, Langade D, Mohod V, Sinha S, Ramteke A, Bakhshi GD, et al. Comparative evaluation of human placental extract for its healing potential in surgical wounds after orthopaedic surgery: an open, randomised, comparative study. J Indian Med Assoc. 2008 Jun;106(6):405-8.

8. Klasen HJ. Historical review of the use of silver in the treatment of burns: early uses. Burns. 2000;26:117-30.

9. Patra CR, Bhattacharya R, Wang E. Targeted delivery of gemcitabine to pancreatic adenocarcinoma using cetuximab as a targeting agent. Cancer Res. 2008;68:1970-8.
10. Silver S. Bacterial silver resistance: molecular biology and uses and misuses of silver compounds. FEMS Microbiol Rev. 2003;27:341-53.

11. Shrivastava S. Characterization of enhanced antibacterial effects of novel silver nanoparticles. Nanotechnology. 2007; 18:225103-12.

12. Gunasekaran T, Nigusse T, Dhanaraju MD. Silver nanoparticles as real topical bullets for wound healing. J Am Coll Clin Wound Spec. 2012 Jun 4;3(4):82-96.

13. Asharani PV, Hande MP, Valiyaveettil S. Antiproliferative activity of silver nanoparticles. BMC Cell Biol. 2009; 10-65.

14. Biswas TK, Auddy B, Bhattacharya NP, Bhattacharya $\mathrm{S}$, Mukherjee B. Wound healing activity of human placental extracts in rats. Acta Pharmacol Sin. 2001 Dec;22(12):1113-6.

Cite this article as: Raju US, Sree TSU, Podila KS, Vijay K. Comparative study of topical application of nanosilver and human placental extract on wound healing in rabbits. Int J Basic Clin Pharmacol 2017;6:1926-31. 